\title{
PENDAMPINGAN UMKM KWT SUKA MAJU UNTUK MENINGKATKAN PRODUKSI DAN PEREKONOMIAN MASYARAKAT DUSUN PALIHAN
}

\author{
Heriyanto', Yuli Fauziah², Dyah Ayu Irawati3 \\ 123 Industrial Engineering Faculty UPN "Veteran" Yogyakarta \\ ${ }^{1}$ Email address heriyanto@upnyk.ac.id; 2 Email address yuli.fauziah@upnyk.ac.id; 3Email \\ address dyah.ayu.irawati@upnyk.ac.id
}

\begin{abstract}
The SUKAMAJU Women's Farmer Group (KWT) is a group of women craftsmen of banana tree processing. During the Covid-19 pandemic, sales and marketing of processed banana food were very limited. Online marketing in times of the Covid-19 pandemic is urgently needed and requires support. Community service from UPN Veteran Yogyakarta, in this case, is programmed to help solve problems during the pandemic. Marketing through the internet and social media is very much needed, while the ability of mothers to master social media and the internet is very limited. The service team from UPN Veteran Yogyakarta is trying to help with solutions going into the field to help provide full assistance and also assistance for production equipment so that food processing craftsmen maintain production in KWT. The hope of the community service team is that there will be an increase in sales results by providing full assistance in both marketing media and increasing production equipment with an average increase of 8-9 pieces per day.
\end{abstract}

Keywords: craftsmen, production, internet, social media

\begin{abstract}
Abstrak
Kelompok Wanita Tani (KWT) SUKAMAJU kelompok ibu-ibu pengrajin olahan pohon pisang. Dimasa pandemic covid-19 penjualan dan pemasaran olahan makanan pisang sangat terbatas. Pemasaran secara online di masa-masa pandemic covid-19 ini sangat di perlukan dan membutuhkan support. Pengabdian masyarakat dari UPN Veteran Yogyakarta dalam hal ini memprogramkan untuk membantu dalam menyelesaikan permasalahan di masa pandemi. Pemasaran melalui internet dan media social sangat dibutuhkan sekali sementara kemampuan ibu-ibu dalam penguasaan media social dan internet sangat terbatas kemampuannya. Tim pengabdian dari UPN Veteran Yogyakarta berusah amembantu dengan solusi terjun ke lapangan untuk membantu memberikan pendampingan penuh dan juga pendampingan peralatan produksi agar pengrajin olahan makanan untuk mempertahankan produksi di KWT. Harapan dari tim pengabdian adalah adanya peningkatan hasil penjualan dengan melakukan pendampingan penuh
\end{abstract}


baik media pemasaran maupun memperbanyak peralatan produksi dengan rata-rata kenaikan 8-9 buah perhari.

Kata kunci: pengrajin, produksi, internet, media social

\section{PENDAHULUAN}

Salah satu KWT di Propinsi Yogyakarta yang giat memanfaatkan atau mengolah hasil-hasil pertanian adalah KWT Suka Maju. KWT Suka Maju beralamat di Dusun Palihan, Desa Sidomulyo, Kecamatan Bambanglipuro, Kabupaten Bantul, Propinsi Yogyakarta. Lokasi KWT Suka Maju terletak di sebelah barat jalan raya Bantul. KWT Suka Maju berjarak sekitar 29,1 km dari Universitas Pembangunan Nasional "Veteran" Yogyakarta, membutuhkan waktu tempuh 56 menit dengan berkendara motor. Sarana transportasi yang bisa digunakan untuk menuju lokasi adalah kendaraan bermotor berupa angkutan umum bis, mobil dan motor. Secara umum, lokasi KWT Suka Maju mudah dijagkau masyarakat.

Pada tahun 2014, jumlah anggota KWT Suka Maju sebesar 43 wanita petani setempat. Dan pada tahun 2015, jumlah anggota KWT Suka Maju telah meningkat menjadi 51 wanita petani setempat. Dengan peningkatan produksi,

KWT Suka Maju membutuhkan media pemasaran yang handal, yaitu: media pemasaran yang murah, mudah, informatif dan mampu menjangkau pasar secara luas. Bagi KWT Suka Maju, media pemasaran yang handal akan meningkatkan jumlah penjualan aneka produk usaha pada masa pandemic covid-19. Pada akhirnya, peningkatan jumlah penjualan aneka produk usaha memberi peningkatan kesejateraan anggota KWT Suka Maju, dan lebih luas akan meningkatkan ekonomi rumah tangga.

\section{METODE DAN PELAKSANAAN}

Bagian ini berisi metode pengabdian dan pelaksanaan kegiatan.

\section{Metode}

Metode berisi metode metode kegiatan dan materi yang disampaikan. beberapa metode kegiatan antara lain: (1) training/pelatihan terkait pembekalan media social dan web; (2) Pendidikan berkelanjutan dengan pelatihan secara berkelanjutan;

penyadaran/peningkatan pemahaman pentingnya penggunaan media social, dan IT; (4) konsultasi dengan memberikan solusi terhadap masalah yang dihadapi dilapangan terkait pemasaran dan penjualan media online. 
Dalam upaya peningkatan ekonomi rumah tangga, setiap anggota keluarga dituntut mampu berusaha produktif menambah pendapatan rumah tangga pada masa pandemic covid-19. Berbeda dengan kelompok tani yang lainnya, kelompok wanita tani dalam pembinaannya diarahkan untuk mempunyai suatu usaha produktif dalam skala rumah tangga yang memanfaatkan atau mengolah hasil-hasil pertanian maupun perikanan, sehingga dapat meningkatkan ekonomi rumah tangga. Selain itu produkstifitas mereka masih terbatas dengan keterbatasan peralatan yang tersedia sementara untuk pemesanan jumlah besar mengalamai kesulitan sehingga perlu diadakan pendampingan dengan mensupport peralatan yang memudahkan dan mempercepat produksi makanan olahan dari pohon pisang

\section{Pelaksanaan Kegiatan}

Pelaksanaan kegiatan meliputi lokasi di Kelompok KWT Sukamaju, Dusun Palihan, Desa Sidomulyo, Kecamatan Bambanglipuro, Bantul DIY pada hari Sabtu dan ahad tanggal 20,21 September 2020, waktu 10.30, jumlah 20 peserta, dan latar belakang belakang peserta ibu-ibu rumah tangga.

\section{HASIL DAN PEMBAHASAN}

Penelitian ini menggunakan perhitungan rata-rata dalam bentuk persentase. Persentase menurut Putra (2011) perhitungan rata-rata yang benar dengan cara jumlah benar dibagi dengan jumlah keseluruhan pencocokan dan dikalikan 100\% begitu juga untuk persentase rata-rata kesalahan. Persentase rata-rata benar dan persentase rata-rata salah menggunakan persamaan (1) dan (2)

$$
h=\frac{g}{0} 100 \% \text {. }
$$

Dalam hal ini, $h$ adalah rata-rata benar, simbol $g$ adalah jumlah benar dan $o$ adalah jumlah keseluruhan pencocokan

$$
A=\frac{q}{0} 100 \% \text {. }
$$

Dalam hal ini, $A$ adalah rata-rata salah, symbol $q$ adalah jumlah salah dan $o$ adalah jumlah keseluruhan pencocokan.

Permasalahan yang ada, anggota dan pengurus KWT Suka Maju belum dapat mengembangkan dan mengelola media sosial. Media sosial sebagai suatu media pemasaran bagi KWT Suka Maju dapat memberikan beberapa hal, sebagai berikut:

1. Peningkatan citra produk usaha KWT Suka Maju dapat dikenal dan diketahui masyarakat serta menambah peralatan untuk memperbanyak produksi dan 
peningkatan produksi secara cepat dan efisien.

2. Sistem penyampaian informasi dan komunikasi kepada masyarakat dapat terlaksana untuk mempublikasikan setiap produk usaha KWT Suka Maju, maka masyarakat sebagai pembeli dan calon pembeli dapat melihat dan mengetahui produk usaha KWT. Sehingga citra produk usaha KWT Suka Maju dapat dikenal dan diketahui masyarakat, dan pada akhirnya menambah penjualan produk usaha KWT Suka Maju.

3. Penumbuhan kepercayaan masyarakat terhadap produk usaha KWT Suka Maju. Dengan memberi informasi pemasaran yang lengkap, seperti: harga, kandungan, ijin dari Dinas Kesehatan, ijin P-IRT, cara pembayaran, mekanisme pengiriman, alamat. Informasi pemasaran yang lengkap dapat menumbuhkan kepercayaan masyarakat terhadap produk usaha KWT Suka Maju.

Tim PbM akan memberikan pendampingan pengembangan media sosial sebagai media pemasaran. Selain itu, juga mengadakan pendampingan pengelolaan media sosial kepada para anggota dan pengurus KWT Suka Maju. Pendampingan dilakukan Tim PbM dalam rangka membangun kemandirian dan meningkatkan kepercayaan diri anggota dan pengurus KWT Suka Maju untuk mengembangkan dan mengelola sosial media sebagai media pemasaran hasil produksinya.

Kendala yang dihadapi selama pelaksanaan kegiatan Pengabdian masyarakat adalah keterbatasan warga KWT dalam mengoperasikan komputer yang berbasis online untuk pemsasaran produk dan pengadaan peralatan untuk mempercepat produksi olahan pisang. Seluruh warga belum bisa menggunakan interenet dan web belum bisa mengolah gambar dengan corel atau adope photoshop, sehingga perlu masih harus diajarkan dari awal cara mulai menggunakan internet, mengakses dan marketing online, mengambil gambar, mengolah dan mengedit gambar, memembuka aplikasi corel dan photoshop cara memasarkan online dengan toko online memilih desain, layout, dan sebagainya. Tetapi sebelum memulai pelatihan, peserta telah dibekali modul pelatihan, sehingga peserta atau anggota KWT dapat berlatih sendiri di rumah melanjutkan materi yang belum dibahas, dan komunikasi media HP dengan nomor kontak atau WhatApp.

Berdasarkan kondisi saat ini, sebagaimana yang diuraikan pada bagian analisis situasi, maka secara umum dapat dikatakan bahwa media sosial sebagai 
media pemasaran yang cepat, mudah dan tepat belum termanfaatkan. Secara khusus, rumusan masalahnya adalah membangun media sosial sebagai media pemasaran produk usaha KWT Suka Maju secara langsung kepada masyarakat. Kedua pendampingan pengelolaan informasi kepada pengurus dan anggota KWT Suka Maju dan mensupport peralatan yang dapat mempercepat produksi sehingga pemesanan dalam jumlah banyak dapat dilayani. Pendampingan pengembangan dan pengelolaan media sosial sebagai media pemasaran, maka akan memudahkan dan memperluas pemasaran kepada masyarakat sebagai konsumen dan calon konsumen dan meningkatakan percepatan produksi olahan pohon pisang. Dari aspek sumber daya manusia (SDM) terdapat beberapa permasalahan yang dapat dijelaskan sebagai berikut:

1. Keterbatasan SDM anggota KWT Suka Maju dalam mengembangkan produksi dengan kurangnya peraltan dengan waktu produksi dan juga pemasaran dimedia sosial.

2. Keterbatasan SDM memberi kontribusi terhadap rendahnya pemasaran produk usaha KWT ke masyarakat. Dan juga sebaliknya, keterbatasan SDM memberi kontribusi terhadap rendahnya komunikasi (pembelian, penjualan dan pemesanan) dan inovasi dari masyarakat ke KWT Suka Maju.

Berdasar data yang ada, KWT Suka Maju telah berdiri hampir 5 (lima) tahun namun tidak memiliki media pemasaran yang dapat diandalkan. Rendahnya pengetahun akan pemanfaatan media sosial, SDM pengurus KWT Suka Maju tidak mampu mendapat manfaat dari teknologi informasi dan komunikasi (TIK), pada khususnya pemanfaatan media sosial.

Dari aspek pengelolaan informasi produk usaha. Terdapat beberapa permasalahan yang dapat dijelaskan sebagai berikut:

1. Citra produk KWT Suka Maju yang masih kurang dikenal masyarakat. Berdasar pencarian informasi terkait produk KWT Suka Maju di mesin pencarian internet (Google), informasi produk usaha KWT Suka Maju sangatlah sedikit. Berdasar mesin pencarian internet (Google), KWT Suka Maju memiliki produk olahan makanan dari sepohon pisang, yaitu

Tabel 1 Produksi olahan pisang

\begin{tabular}{|l|l|l|}
\hline No & Materi/bahan & \multicolumn{1}{|c|}{ Olahan } \\
\hline $\mathbf{1}$ & $\begin{array}{l}\text { Bonggol } \\
\text { pisang }\end{array}$ & $\begin{array}{l}\text { kerupuk } \\
\text { bonggol, kripik } \\
\text { bonggol, gudeg }\end{array}$ \\
\hline
\end{tabular}




\begin{tabular}{|l|l|l|}
\hline & & $\begin{array}{l}\text { bonggol, dan } \\
\text { dendeng } \\
\text { bonggol }\end{array}$ \\
\hline 2 & Daun pisang & $\begin{array}{l}\text { pewarna alami } \\
\text { untuk dawet } \\
\text { yang terbuat } \\
\text { dari tepung } \\
\text { pisang }\end{array}$ \\
\hline 3 & $\begin{array}{l}\text { Jantung } \\
\text { pisang }\end{array}$ & $\begin{array}{l}\text { dibuat kripik } \\
\text { jantung pisang } \\
\text { dan sayur lodeh } \\
\text { jantung }\end{array}$ \\
\hline 4 & Buah pisang & $\begin{array}{l}\text { dodol pisang, } \\
\text { sale pisang dan } \\
\text { tepung pisang, }\end{array}$ \\
\hline
\end{tabular}

2. Permasalahan yang ada dikarenakan KWT Suka Maju tidak memiliki media sosial sebagai media pemasaran produk kepada masyarakat.

Kurang terpercayanya aneka produk usaha KWT Suka Maju di masyarakat. KWT Suka Maju tidak memberi penjelasan yang bisa dipercaya dan rinci akan produk usahanya. Berdasar mesin pencarian internet (Google), olahan makanan dari sepohon pisang, yaitu dari bonggol, daun pisang, jantung pisang, dan buah pisang matang. Bonggol pisang dapat dibuat kerupuk bonggol, kripik bonggol, gudeg bonggol, dan dendeng bonggol. Daun pisang dapat dibuat sebagai pewarna alami untuk dawet yang terbuat dari tepung pisang.
Jantung pisang dapat dibuat kripik jantung pisang dan sayur lodeh jantung. Buah pisang dapat dibuat dodol pisang, sale pisang dan tepung pisang. namun demikian tidak ada informasi terkait: komposisi produk, kandugan gizi, jaminan mutu produk, sertifikat halal, perijinan produk serta testimoni pembeli manfaat dan kegunaan makanan yang sehat selain itu kemampuan produksi yang belum cepat sehingga keterbatasan alat untuk mempercepat produksi juga menjadi kendala. Penyelesaian permasalahan KWT Suka Maju yang juga terdampak pandemi Covid-19 dan telah diuraikan pada bagian sebelumnya, diusulkan solusi alternatif kegiatan secara online yang dapat dijelaskan sebagai berikut:

Dari kegiatan pendampingan pengembangan dan pengelolaan media sosial sebagai media pemasaran bagi produk usaha Kelompok Wanita Tani (KWT Suka Maju yang dilaksanakan, maka target luaran diharapkan adanya perubahan aliran informasi dan komunikasi produk usaha KWT Suka Maju yang menjadi lebih baik, menarik, cepat, tepat, luas dan berlangsung dua arah, yaitu:
a. KWT Suka Maju kepada masyarakat (penjualan dan pemasaran produk)
b. Masyarakat kepada KWT Suka Maju (pemesanan dan ide inovasi produk) 
c. Peningkatan penjualan produk usaha KWT Suka Maju

Pengembangan alternatif media informasi dan komunikasi dalam pemasaran produk usaha Kelompok KWT Sukamaju Dusun Palihan Desa Sidomulyo, kecamatan Bamanlipuro, Bantul menjadi aman, lebih baik, menarik, cepat, dalam produksi tepat dan luas di tengah mewabahnya pandemi Covid-19, yaitu dengan penguasan teknik pengembangan multimedia dan online terkait produk makanan olahan pohon pisang. Peningkatan produk secara cepat dengan support peralatan kepada usaha Kelompok KWT Sukamaju, Dusun Palihan, Desa Sidomulyo, Kecamatan Bambanglipuro, Bantul DIY

Tabel 1 Perbandingan Pemesanan online dan sebelum online

\begin{tabular}{|l|l|l|l|l|l|}
\hline \multirow{2}{*}{ No } & \multirow{2}{*}{ Item } & \multicolumn{2}{l|}{$\begin{array}{l}\text { Pemesanan } \\
\text { Online }\end{array}$} & $\begin{array}{l}\text { Sebelum } \\
\text { Online }\end{array}$ & Selisih \\
\cline { 3 - 6 } & & $\begin{array}{l}\text { Bulan } \\
\text { Tahun } \\
2020\end{array}$ & $\begin{array}{l}\text { Rata- } \\
\text { rata } \\
\text { /hari }\end{array}$ & $\begin{array}{l}\text { Rata- } \\
\text { Rata } \\
/ \text { hari }\end{array}$ & terjual \\
\hline 1 & A01 & Januari & 20 & $10 /$ hari & 10 \\
\hline 2 & A01 & Februari & 15 & $9 /$ hari & 6 \\
\hline 3 & A01 & Maret & 18 & $10 /$ hari & 8 \\
\hline 4 & A01 & April & 19 & 10 & 9 \\
\hline 5 & A01 & Mei & 20 & 8 & 12 \\
\hline 6 & A01 & Juni & 22 & 8 & 14 \\
\hline 7 & A01 & Juli & 17 & 12 & 5 \\
\hline 8 & A01 & Agustus & 18 & 13 & 5 \\
\hline & & & & Rata- & 8,625 \\
& & & & Rata & Atau 9 \\
\hline
\end{tabular}

\section{PENUTUP}

\section{Simpulan}

Secara keseluruhan pemahaman mengenai marketing online dengan mengedepankan tampilan layout item dan mempunyai fungsi makanan dan kesehatan dapat membantu menaikan tingkat produksi di KWT. Sedangkan masih ada keterbatasan ketersediaan alat produksi dan sangat diperlukan bagi warga dan KWT karena saat produksi meningkat dengan media online maka harus didukung supply yang baik dari produksi agar terpenuhi dengan jumlah yang banyak secara cepat dan efisien. Pendampingan dengan memberikan sejumlah peralatan dapat meningkatkan produksi dan menaikan tingkat pendapatan di KWT desa Palihan dengan rata-rata setiap hari bertambah 8,6 item atau 9 item terjual setiap hari.

\section{Saran}

Penggunaan web dan social media perlu di lakukan evaluasi secara periodick setiap enam bulan sekali untuk keberlanjutan.

\section{Ucapan Terima Kasih}

Kegiatan ini terlaksana berkat sponsor dari pengabdian LP3M UPN "Veteran" Yogyakarta dan juga ibu-ibu KWT. 


\section{DAFTAR PUSTAKA}

Arifin, Y \& Ricky, MY \& Yesmaya, V, 2015, Digital Multimedia, Bina Nusantara Media \& Publishing

Dewi, Ni Luh AFM. 2011. Pengaruh Usaha Kelompok Wanita Tani "Mekar Usaha" terhadap Pendapatan Keluarga di Banjar Dinas Saren Kauh, Desa Budakeling. Universitas Pendidikan Ganesha, Singaraja.

Ekaningdyah, Astrid. 2005. Peran Wanita dalam Peningkatan Pendapatan Keluarga Nelayan di Desa Tasikagung, Kecamatan Rembang, Kabupaten Rembang, Jawa Tengah. Universitas Diponegoro, Semarang.

Petrus Katemba, Rosita Koro Djoh, Prediksi Tingkat Produksi Kopi Menggunakan Regresi Linear, Jurnal Ilmiah FLASH Volume 3 Nomor 1 Juni 2017

Putra, A.E., 2008. Frekuensi Cuplik pada FFT. Tan Li, Processing, Digital Signal, 1.

Putra, D. dan Adi, R., 2011. Verifikasi
Biometrika, Biometrika, Universitas Udayana, 2(1), hal.821.

Sasongko, AK., 2012, diunduh dari e-journal.uajy.ac.id pada 23 Maret 2018, pukul 09.33 WIB Tahalea, Silviana, 2016, Fotografi Produk Sebagai Sarana Promosi Produk Lampu untuk Perajin Lampu di Nitiprayan Yogyakarta. Seminar Nasional Pengabdian Kepada Masyarakat-Fakultas Seni Rupa dan Desain Universitas Trisakti.

Wulandari, NT \& Darwanto, DH \& Irham, 2015, Analysis of Added Value and Contribution of Bamboo Craft Industry to Society's Income Distributionin Sleman District, Agro Ekonomi Vol. 26/No. 2

Yahya, Kurnia, 2018, Alir Proses Produksi Produk Multimedia, diunduh dari http://kurnia.nireblog.com pada 23 Maret 2018, pukul 09.33 WIB 